\title{
Mechanism identification of temperature influence on mercury adsorption capacity of different halides modified bio-chars
}

Guoliang Li ${ }^{\text {a, b }}$, Shuxiao Wang ${ }^{\text {a, b* }}$, Qingru Wu ${ }^{\text {a, b }}$, Fengyang Wang ${ }^{\text {a, b }}$, Dian Ding ${ }^{\text {a, b }}$ and Boxiong Shen $^{\mathrm{c}}$

${ }^{a}$ State Key Joint Laboratory of Environment Simulation and Pollution Control, School of Environment, Tsinghua University, Beijing 100084, China

${ }^{b}$ State Environmental Protection Key Laboratory of Sources and Control of Air Pollution Complex, Beijing 100084, China

${ }^{c}$ School of Energy \& Environmental Engineering, Hebei University of Technology, Tianjin 300401, China

\begin{abstract}
Bio-chars as mercury sorbent were derived from cotton straw via pyrolysis carbonization, microwave/steam activation and ammonium halides impregnation. Mercury adsorption capacity of various impregnated bio-chars was tested at different temperatures. Rising temperature improved the adsorption capacity of bio-chars modified with $\mathrm{NH}_{4} \mathrm{Br}$ and $\mathrm{NH}_{4} \mathrm{I}$ yet inhabited that of bio-char modified with $\mathrm{NH}_{4} \mathrm{Cl}$. Kinetic model analysis indicated that the changes of mercury adsorption capacity were related to the difference of enthalpy change for various bio-chars. In temperature programmed desorption technic (TPDT) analysis, high desorption energy (80.9-82.1 $\mathrm{kJ} \cdot \mathrm{mol}^{-1}$ ) proved that mercury adsorption mainly depended on chemisorption for halide modified bio-chars. Modification effect of ammonium halides on mercury adsorption capacity followed the order: $\mathrm{NH}_{4} \mathrm{I}\left(7643.1 \mu \mathrm{g} \cdot \mathrm{g}^{-1}\right)>\mathrm{NH}_{4} \mathrm{Br}\left(842.0 \mu \mathrm{g} \cdot \mathrm{g}^{-1}\right)>$ $\mathrm{NH}_{4} \mathrm{Cl}\left(365.3 \mu \mathrm{g} \cdot \mathrm{g}^{-1}\right)$. X-ray photoelectron spectroscopy (XPS) analysis proved that $\mathrm{C}-\mathrm{X}$ groups served as mercury adsorption sites and determined the mercury removal capacity of bio-chars. This study explained the mechanism of temperature effects and halides modification as well as proposed useful suggestion on mercury sorbent preparation and application.
\end{abstract}

Keyword: bio-char; mercury adsorption; kinetic model; desorption energy

\section{Introduction}

* Corresponding author: Professor Shuxiao Wang.

E-mail: shxwang@tsinghua.edu.cn Fax: +861062773650 
The fossil fuel combustion is an important anthropogenic source for mercury emission [1]. The mercury from combustion flue gas exists in three forms: particle-bound mercury $\left(\mathrm{Hg}^{\mathrm{P}}\right)$, oxidized mercury $\left(\mathrm{Hg}^{2+}\right)$ and elemental mercury $\left(\mathrm{Hg}^{0}\right)$. $\mathrm{Hg}^{2+}$ and $\mathrm{Hg}^{\mathrm{P}}$ can be captured by synergic $\mathrm{Hg}$ removal techniques, such as flue gas desulfurization (FGD) system and dust collectors [2, 3]. Conversely, elemental mercury is very difficult to be removed because of its high vapor pressure and low water solubility [4]. Therefore, people pay much attention to the emission of $\mathrm{Hg}^{0}$ due to its volatility, high toxicity, bioaccumulation in the environment [5]. The technology of activated carbon (AC) injection has been commercially applied to reducing $\mathrm{Hg}^{0}$ emissions from coal combustion system. However, the high cost for AC injection is the main obstacle to prevent its further popular application [6, 7]. Consequently, various low-cost carbonaceous sorbent materials as AC alternatives were extensively studied, such as mulberry twig [8], bamboo [9], coconut shells [10] and coke [11].

Original pyrolysis products performed a poor mercury adsorption capacity and hence various physical and chemical modification methods were used to improve their adsorption property. The halides were usually selected and considered as effective modification reagent in previous studies [8, 12-14]. Various halides modified $\mathrm{AC}$ and bio-chars have widely used in the coal-fired power plants. The sorbent injection point usually contains two positions: before electrostatic precipitation (ESP) and after ESP (TOXECON Techology). The sorbent injection position is often placed between Selective Catalytic Reduction (SCR) and ESP equipment. The flue gas temperature from injection point to ESP outlet is in the range of $200-130{ }^{\circ} \mathrm{C}$. TOXECON Technology added a fabric filter (FF) after ESP, which can effectively separate carbon-based sorbents from ash and reduce sorbent negative influence on ash recycling. The flue gas temperature further decreases with the flue gas flow. For TOXECON Technology, the flue gas temperature from AC injection point to FF outlet is in the range of $110-80{ }^{\circ} \mathrm{C}$. Therefore, the flue gas temperature of sorbent injection point shows obvious difference between two technologies, which possibly plays an inportant role on mercury adsorpiton capacity of carbon-based sorbents [15]. However, few studies had comprehensively considered and researched the influence of flue gas 
temperature on halides modified sorbents in practical application. Moreover, the adsorption mechanism of testing temperature influence on halides modified bio-chars was still inconsistent and ambiguous. It is known that the increase of temperature improves chemisorption yet inhabits physisorption since high temperature helps to reach chemisorption reaction energy and low temperature makes for mercury condensation. This was proved in Cai's and De's studies, that is, high temperature (180-195 ${ }^{\circ} \mathrm{C}$ ) improved the mercury adsorption performance of halides modified sorbents $[12,13]$. However, some studies suggested that rising the temperature in the range of 80-160 ${ }^{\circ} \mathrm{C}$ could decrease the mercury adsorption efficiency and adsorption capacity of chloride modified bio-char [14], which confirms to physisorption property. Thereby, whether physisorption or chemisorption determines the adsorption performance of halide modified bio-chars at various reaction temperatures is still unclear and needs to be explored.

In this study, the cotton straw and ammonium halides were selected as the raw material and modified reagents, respectively, since the cotton straw and ammonium halides were proven to be an optimal selection from three raw materials (municipal solid wastes, industrial wastes, and cotton straw) and three modified reagents $\left(\mathrm{NH}_{4} \mathrm{Cl}\right.$, $\mathrm{HCl}$, and $\mathrm{ZnCl}_{2}$ ) in our previous studies $[16,17]$. The effect of different halides modification, loading and testing temperature was further investigated on the mercury capture experiment. The proximate and ultimate analyses, pore analysis, SEM, TPDT and XPS characterization were conducted to analyze the property and adsorption mechanism of bio-chars. Kinetic model and thermodynamic parameters were calculated to further investigate the reaction mechanism of halides modified bio-chars under various testing temperatures.

\section{Materials and Methods}

\subsection{Sample preparation}

After natural drying, the raw materials (cotton straw) was shredded and crushed to a size of 8.0-10.0 mm. The cotton straw chipping was placed in a quartz reactor (160 $\mathrm{mm}$ in diameter and $400 \mathrm{~mm}$ in depth) under a $\mathrm{N}_{2}$ atmosphere with $200 \mathrm{~mL} \cdot \mathrm{min}^{-1}$. The reactor was steadily heated to desired pyrolysis temperature of $600{ }^{\circ} \mathrm{C}$ at 20 
${ }^{\circ} \mathrm{C} \cdot \mathrm{min}^{-1}$ and remained for $60 \mathrm{~min}$. Then, the pyrolysis reactor was cooled to room temperature under the oxygen-free environment. The derived bio-char was denoted as C6.

The microwave and steam activation can remove the ash and improve the pore structure of bio-char. The pore development is beneficial to mercury physisorption and offering adsorption sites for modificaiton reagents [16]. The above-mentioned bio-char $(2.0 \mathrm{~g})$ was placed in a quartz bottle reactor $\left(50 \mathrm{~cm}^{3}\right)$ under oxygen-free atmosphere with a constant flow of $\mathrm{N}_{2}\left(80 \mathrm{~mL} \cdot \mathrm{min}^{-1}\right)$. Deionized water was injected into the bottle reactor to generate steam under the control of the peristaltic pump. The whole bottle reactor was placed in a microwave oven (power: $950 \mathrm{~W}$ ). The bio-char C6 was activated by the microwave and steam for $4 \mathrm{~h}$. The derived bio-char was denoted as C6W.

The bio-char C6W was impregnated with various additives solutions of uniform concentration of $0.05 \mathrm{~mol} \cdot \mathrm{L}^{-1}$, including $\mathrm{NH}_{4} \mathrm{Cl}, \mathrm{NH}_{4} \mathrm{Br}$ and $\mathrm{NH}_{4} \mathrm{I}$. Two liquid-solid ratios $\left(4 \mathrm{~mL} \cdot \mathrm{g}^{-1}\right.$ and $\left.20 \mathrm{~mL} \cdot \mathrm{g}^{-1}\right)$ were adopted to obtain the molar loading of halides in the range of 0.2-1.0 mol\% of bio-chars. Various liquid-solid mixtures were stirred for $12 \mathrm{~h}$ and then dried at a water bath at $80{ }^{\circ} \mathrm{C}$. The mixtures were further dried at an oven for $12 \mathrm{~h}$ at $105{ }^{\circ} \mathrm{C}$. The following abbreviation was used to introduce different additives modified bio-chars: C6WNXY. The X represents the species of ammonium halides $(\mathrm{X}: \mathrm{Cl}, \mathrm{Br}$ and $\mathrm{I})$ and $\mathrm{Y}$ represents the molar loading $(0.2$ and $1.0 \mathrm{~mol} \%)$ of halides (Y: 0.2 and 1). Therefore, the derived bio-chars modified various additives were denoted as C6WNC10.2, C6WNCl1, C6WNBr0.2, C6WNBr1, C6WNI0.2 and C6WNI1, respectively.

\subsection{Characterization techniques}

The proximate analysis of cotton straw was measured according to the method of Chinese National standards (GB/T 212-2008). Elementar EA3000 (LEEMAN, China) was used to measure the ultimate analysis of cotton straw. Specific surface area $\left(\mathrm{S}_{\mathrm{BET}}\right)$, micropore specific surface area $\left(\mathrm{S}_{\mathrm{BETmicro}}\right)$, the ratio of $\mathrm{S}_{\mathrm{BETmicro}}$ to $\mathrm{S}_{\mathrm{BET}}(\mathrm{S} \%)$, pore volume $\left(\mathrm{V}_{\text {total }}\right)$, micropore volume $\left(\mathrm{V}_{\text {micro }}\right)$, the ratio of $\mathrm{V}_{\text {micro }}$ to $\mathrm{V}_{\text {total }}(\mathrm{V} \%)$ and pore diameters (D), were measured by $\mathrm{N}_{2}$ adsorpiton at $-196{ }^{\circ} \mathrm{C}$ on a ASAP 2020 
automated gas adsorption system (Micromeritics, USA). The surface morphology of bio-chars was analyzed by the Scanning electron microscope SSX-550 (SHIMADZU CO. ltd, Japan). The element $(\mathrm{Cl}, \mathrm{Br}$, I and $\mathrm{Hg}$ ) valence state on the surface of bio-chars was analyzed by X-ray photoelectron spectroscopy (XPS) using Axis Ultra DLD (Kratos Analytical Ltd, Britain) with Mg X-ray source. All binding energies were calibrated by the $\mathrm{C} 1 \mathrm{~s}$ peak at $284.6 \mathrm{eV}$. The temperature programmed desorption technic (TPDT) was used to analyze the desorption energy of mercury adsorbed on various bio-char. The TPDT schematic and operation detail was shown in Fig. S1.

\subsection{Mercury adsorption testing}

The setup of the mercury adsorption testing used to evaluate the mercury adsorption performance of various bio-chars was shown in Fig. S2. The testing devices contain an elemental mercury generator, a fixed-bed reactor, temperature-controlled heating equipment, an online mercury analyzer, and a gas flue cleaner. The mercury vapor was generated from $\mathrm{Hg}^{0}$ permeation tube when an $\mathrm{N}_{2}$ flow, serving as carrier gas, passed through the permeation tube within a U-type glass tube. The U-type glass tube was placed in a temperature-controlled thermostat water bath to remain $\mathrm{Hg}^{0}$ concentration at $29.0 \pm 1 \mu \mathrm{g} \cdot \mathrm{m}^{-3}$. In order to avoid the oxidation influence of acid and oxidizing gases, only the $\mathrm{N}_{2}$ served as the balance gas to keep the total inlet gas flow at $850 \mathrm{~mL} \cdot \mathrm{min}^{-1}$. The quartz fixed bed was heated by electricity controlled at 60,120 and $180{ }^{\circ} \mathrm{C} .5 .0 \mathrm{mg}$ char was mixed with $0.5 \mathrm{~mL}$ silica sand and then placed the mixture in the adsorption zone of reactor. The space velocity was $100,000 \mathrm{~h}^{-1}$, which is similar to those used in industries. The whole gas line was kept warm to avoid $\mathrm{Hg}^{0}$ condensation. The elemental mercury concentration at the inlet and outlet of the reactor was online measured by the H11-QM201H cold vapor atomic analyzer (Jiangsu, China). The mercury adsorption testing was stopped until the bio-chars reached the adsorption equilibrium or the testing time reached $1600 \mathrm{~min}$.

The efficiency $(\eta)$ of the sorbent was calculated according to Eq. (1).

$$
\eta=\frac{C_{\text {in }}-C_{\text {out }}}{C_{\text {in }}} \times 100 \% \quad \text { Eq. (1) }
$$


where, $\eta$ is $\mathrm{Hg}^{0}$ removal efficiency, which is the average of two parallel experimental data and the relative error of all parallel experimental data is less than $8 \% . C_{\text {in }}$ and $C_{\text {out }}$ $\left(\mu \mathrm{g} \cdot \mathrm{Nm}^{-3}\right)$ are $\mathrm{Hg}^{0}$ concentrations at the inlet and outlet of the fixed-bed reactor, respectively.

The activity of the sorbent was determined by $\mathrm{Hg}^{0}$ adsorptive capacity $q_{t}\left(\mu \mathrm{g} \cdot \mathrm{g}^{-1}\right)$ according to Eq. (2).

$$
q_{t}=\frac{F \times C_{i n} \times \int_{0}^{t} \eta d t}{W}
$$

where, $F$ is the gas flow rate $\left(\mathrm{Nm}^{3} \cdot \mathrm{min}^{-1}\right), W$ is the mass of sorbent $(\mathrm{g})$ and $t$ is the adsorption time.

\section{Results and Discussion}

\subsection{Sample characterization}

\subsubsection{Proximate and ultimate analysis}

The result of proximate and ultimate analysis for cotton straw was shown in Table 1. According to the proximate analysis, the content of moisture was only $0.2 \%$, which was possibly attributed to prior natural drying. The ash content of cotton straw was also relatively low while the volatile and fixed carbon (FC) was relatively high, compared with other materials, such as coal [18]. Our previous study has proved that low ash and high volatile content are beneficial to the development of pore structure of the char during pyrolysis process [16]. As shown in ultimate analysis, the $\mathrm{H}$ and $\mathrm{N}$ content were very small, but the content of $\mathrm{C}$ and $\mathrm{O}$ element was relatively high in cotton straw. The high $\mathrm{C}$ and $\mathrm{O}$ content contributed to the growth of oxygen-containing functional groups, which made for $\mathrm{Hg}^{0}$ adsorption [19].

\subsubsection{Pore analysis}

As shown in Table 2, the microwave activation and chemical impregnation played an important role on the pore parameter of bio-chars. The original bio-char C6 presented a good performance in the pore structure, indicating that good property of cotton straw facilitated the development of pore structure during pyrolysis as shown 
in Table 1. Furthermore, the microwave and steam activation further improved the pore property. The ash removal by microwave action increased the pore volume and specific surface area of bio-chars $[20,21]$. On the contrary, the loading of ammonium halides inhabited pore property of bio-chars. The $\mathrm{NH}_{4} \mathrm{I}$ and $\mathrm{NH}_{4} \mathrm{Cl}$ loading decreased the specific surface area in the range of $65.5-294.9 \mathrm{~m}^{2} \cdot \mathrm{g}^{-1}$ and $29.4-269.1 \mathrm{~m}^{2} \cdot \mathrm{g}^{-1}$, respectively." Similarly, the increase of $\mathrm{NH}_{4} \mathrm{Br}$ impregnation decreased the specific surface area in the range of $4.2-234.9 \mathrm{~m}^{2} \cdot \mathrm{g}^{-1}$. The similar phenomenon was also seen in the micropore area, pore volume and micro volume. In addition, after the halide modification, the ratio $(\mathrm{S} \%)$ of $\mathrm{S}_{\mathrm{BETmicro}}$ to $\mathrm{S}_{\mathrm{BET}}$ and the ratio $(\mathrm{V} \%)$ of $\mathrm{V}_{\text {micro }}$ to $\mathrm{V}_{\text {total }}$ obviously declined and the diameter evidently rose compared with that of the bio-char C6W. It indicated that ammonium halides impregnation possibly concentrated on the micropore region, resulting in increasing the pore diameters and declining the S\% and $\mathrm{V} \%$.

In order to further analyze the influence of ammonium halides on the pore structure, the pore distribution of C6, C6W, C6WNI0.2 and C6WNI1 was shown in Fig. 1. To reduce the influence of the fictitious bottle in the desorption branch caused by the tensile strength effect (TSE) of mesopores, the pore distribution was calculated on the basis of the adsorption branch [22]. The inset of pore distribution in the range of 0-0.003 $\mathrm{cm}^{3} \cdot \mathrm{g}^{-1}$ was inserted into Fig. 1 to further exhibit the pore character in mesopore and macropore. As shown in the inset of Fig. 1, the pores of C6 were well-balanced and distributed in the micropore, mesopore and macropore regions. But after microwave and steam action, the distribution plot of bio-char C6W became steep over the micropore and flat over the mesopore and macropre, indicating the pore volume concentrated on the micropore region. Nevertheless, after the halide impregnation, the curve of C6WNI0.2 showed a relatively mild climb over micropore region and that of C6WNI1 expressed a milder climb over micropore region, indicating that chemical reagent intensively blocked the micropore region of bio-char. This result verified the conclusion that ammonium halides impregnation focused on the reduction of the micropore volume. 


\subsubsection{SEM analysis}

The SEM images of prior and after $\mathrm{NH}_{4} \mathrm{I}$ impregnated bio-chars were shown in Fig. 2(A-C) to further investigate the surface structure of bio-chars. Fig. 2A indicates that the surface of C6W has excellent pore structure after the microwave activation. In contrast, there were particulate matters aggregating on the surface of C6WNI0.2 and partially blocking pore structure, as shown in Fig. 2B. When the loading further increased, a layer of dense $\mathrm{NH}_{4} \mathrm{I}$ reagent absolutely covered all pore structure on the surface of bio-chars in Fig. 2C. This is supported by the EDS analysis in Fig. S3 and Table S1. The result of SEM analysis confirms to the conclusion in pore analysis that the increase of impregnation loading could block the pore structure and reduce the pore volume.

\subsection{Mercury adsorption testing}

\subsubsection{Effect of halides modification on $\mathrm{Hg}^{0}$ adsorption}

To compare modification effect of bio-chars impregnated by three ammonium halides, their mercury adsorption performance was shown in Fig. 3. In general, the adsorption capacity for three modified bio-chars all enhanced obviously compared to 7.5 and $30.0 \mu \mathrm{g} \cdot \mathrm{g}^{-1}$ for C6 and C6W [16], suggesting that chemical modification greatly improved the mercury adsorption capacity of bio-chars. The equilibrium adsorption capacity of $\mathrm{C} 6 \mathrm{WNCl} 0.2$ reached $365.3 \mu \mathrm{g} \cdot \mathrm{g}^{-1}$ and that of $\mathrm{C} 6 \mathrm{WNBr} 0.2$ reached $842.0 \mu \mathrm{g} \cdot \mathrm{g}^{-1}$. Moreover, the bio-char C6WNI0.2 did not reached adsorption equilibrium and its mercury adsorption efficiency surpassed $90 \%$ at whole adsorption testing (1600 min). The adsorption capacity of C6WNI0.2 reached $7643.1 \mu \mathrm{g}^{-1} \mathrm{~g}^{-1}$ at the end of adsorption testing. The bio-char C6WNI0.2 with a poor pore structure showed a better adsorption capacity than the C6WNCl0.2 and C6WNBr0.2. The pore structure seems not a key factor affecting the mercury adsorption of halides modified bio-char. Moreover, these testing results indicated that mercury adsorption capacity of bio-chars mainly depended on modification halide species. Their modified effect followed the order: $\mathrm{NH}_{4} \mathrm{I}>\mathrm{NH}_{4} \mathrm{Br}>\mathrm{NH}_{4} \mathrm{Cl}$. Previous study suggested that excellent performance of iodide-modification was attributed to its bigger atomic radius 
resulting in higher surface exposure to mercury, which increased the reaction probability of $\mathrm{Hg}$ atom and $\mathrm{I}^{-}$ion [13]. However, the difference value of ion radius

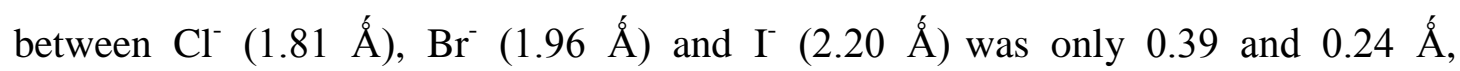
respectively, which might not have much influence on their adsorption capacity. As a result, the mercury adsorption mechanism was necessary to further discussed at other aspects.

\subsubsection{Effect of the loading on $\mathrm{Hg}^{0}$ adsorption}

In order to further investigate the effect of different loading on the adsorption performance, the adsorption capacity of bio-chars modified by three ammonium halides was shown in Fig. 4. As shown in Fig. 4, the loading increase of three ammonium halides all evidently improved mercury adsorption capacity of bio-chars. The bio-chars C6WNC11 and C6WNBr1 possessed greater equilibrium adsorption capacity (1239.2 $\mu \mathrm{g} \cdot \mathrm{g}^{-1}$ and $2781.9 \mu \mathrm{g} \cdot \mathrm{g}^{-1}$, respectively) than the C6WNCl0.2 and C6WNBr0.2. The mercury adsorption capacity of C6WNI0.2 and C6WNI1 were not significantly different since their mercury adsorption efficiency was similar at the whole testing procedure. It should be noted that rising loading decreased the pore property but increased the mercury adsorption capacity. These results suggested that the loading increase possibly could offer more chemical sites for elemental mercury adsorption.

\subsubsection{Effect of testing temperature on $\mathrm{Hg}^{0}$ adsorption}

Fig. 5 showed different effect of testing temperature on $\mathrm{Hg}^{0}$ adsorption capacity of bio-chars modified by various halides. In Fig. 5B and Fig. 5C, the mercury adsorption performance of C6WNBr0.2 and C6WNI0.2 was similar and obviously went up from $60{ }^{\circ} \mathrm{C}$ to $180{ }^{\circ} \mathrm{C}$. In the range of $60-180{ }^{\circ} \mathrm{C}$, the adsorption capacity increased from $631.7 \mu \mathrm{g} \cdot \mathrm{g}^{-1}$ to $3089.4 \mu \mathrm{g} \cdot \mathrm{g}^{-1}$ for C6WNBr0.2 and from $5337.6 \mu \mathrm{g} \cdot \mathrm{g}^{-1}$ to $7752.0 \mu \mathrm{g} \cdot \mathrm{g}^{-1}$ for C6WNI0.2. This result was consistent with common theory that rising temperature in the range of $20-180{ }^{\circ} \mathrm{C}$ was beneficial to the chemisorption of mercury since high temperature easily met the reaction energy of chemisorption $[9,14]$. On the contrary, 
the mercury adsorption capacity of C6WNCl0.2, as shown in Fig. 5A, decreased from $1118.9 \mu \mathrm{g} \cdot \mathrm{g}^{-1}$ to $335.2 \mu \mathrm{g} \cdot \mathrm{g}^{-1}$ at the range of $60-180{ }^{\circ} \mathrm{C}$. It was opposite to above theory that the temperature rising promoted chemisorption reaction. According to above testing results, the halide modified bio-chars seemed to adsorb elemental mercury on the basis of different adsorption mechanism. In order to further investigate and verify the adsorption mechanism, the kinetic models were used to further analyze.

\subsection{Kinetic model analysis}

Diversified kinetic models, such as pseudo-first order model, intra-particle diffusion equation, pseudo-second order model and Elovich kinetic equation, had been used to explore and determine the mechanism of the mercury adsorption process $[23,24]$. The pseudo-first order model and intra-particle diffusion model concentrated on the mechanism study of mass transfer and inter diffusion process, respectively [23]. The pseudo-second order and Elovich models investigated the process of surface reaction and catalytic reaction. Therefore, the $\mathrm{Hg}^{0}$ mass transfer process from gas phase to adsorption sites was more likely to match with the pseudo-first order model while the chemisorption for $\mathrm{Hg}^{0}$ was in accord with pseudo-second order model [23-25]. Considering the purpose of this study to distinguish and ascertain the main adsorption mechanism of modified bio-chars, the pseudo-first and pseudo-second order models were used to simulate the mercury adsorption process and determine the adsorption mechanism.

The pseudo-first order equation can be described by Eq. (3) [23].

$$
\lg \left(q_{e}-q_{t}\right)=\lg q_{e}-\frac{k_{1}}{2.303} t \quad \text { Eq. (3) }
$$

where, $q_{t}$ and $q_{e}$ represent the amount of adsorbate $\left(\mu \mathrm{g} \cdot \mathrm{g}^{-1}\right)$ at time $t$ and at equilibrium time, respectively, and $k_{1}$ represents the rate constant of first order equation $\left(\min ^{-1}\right)$.

The kinetic rate equation for the pseudo-second order was expressed by Eq. (4).

$$
\frac{t}{q_{t}}=\frac{1}{k_{2} q_{e}^{2}}+\frac{1}{q_{e}} t \quad \text { Eq. (4) }
$$


where, $q_{t}$ and $q_{e}$ have the same meaning as those in Eq.(3), and $k_{2}$ represents the adsorption reaction rate constant $\left(\mathrm{g} \cdot \mu \mathrm{g}^{-1} \cdot \mathrm{min}^{-1}\right)$.

The experimental data of three bio-chars in different temperature was fitted with the pseudo-first and pseudo-second order models. The result was shown in Fig. 6 and specific fitting correlation coefficient $\left(R^{2}\right)$ was listed in Table 3.

As shown in Fig. 6, three bio-char modified by various halides had much difference in the fitting result of pseudo-first and pseudo-second order models. In Table 3, for three modified bio-chars, the correlation coefficient of pseudo-second was all over 0.96. Moreover, combining Table 3 with Fig. 6, it was noteworthy that when the correlation coefficient of pseudo-second rose, mercury adsorption capacity for all bio-chars increased accordingly. These results illustrated that the mercury adsorption capacity of bio-chars possibly depended on the chemisorption. However, the temperature rising had different influence on the fitting result and adsorption capacity. The high temperature improved fitting correlation coefficient of pseudo-second for C6WNBr0.2 and C6WNI0.2 yet decreased that for C6WNCl0.2. In addition, the temperature change also played different role on the fitting correlation coefficient of pseudo-first order model. The high temperature lowered the $R^{2}$ of pseudo-first order model of C6WNBr0.2 and C6WNI0.2 since the temperature rising inhabited the physisorption occurrence. However, for $\mathrm{C} 6 \mathrm{WNCl0.2}$, the fitting correlation coefficient of pseudo-first order model reached lowest point $(0.63)$ at $60{ }^{\circ} \mathrm{C}$. These results implied that the chemisorption mechanism for the temperature change was different between C6WNBr0.2, C6WNI0.2 and C6WNCl0.2. According to previous study, the thermodynamic property possibly affected the adsorption reaction $[14,26]$. In order to further investigate the adsorption mechanism of different bio-chars, the enthalpy change $\left(\Delta H^{\circ}\right)$ was calculated to reflect the effect of temperature change.

The enthalpy change $\left(\Delta H^{\circ}\right)$ could be obtained using the data from pseudo-second order model according to Eq. (5).

$$
\ln K_{D}=\frac{\Delta S^{o}}{R}-\frac{\Delta H^{o}}{R T}
$$


where $K_{D}$ represents the distribution coefficient of sorbent, which is equal to $q_{e} \cdot C_{e}^{-1}$; $C_{e}$ represents the initial concentration of elemental mercury; $\Delta S^{\circ}$ represents standard entropy $\left(\mathrm{J} \cdot \mathrm{mol}^{-1} \cdot \mathrm{K}^{-1}\right) ; \Delta H^{\circ}$ represents standard enthalpy $\left(\mathrm{kJ} \cdot \mathrm{mol}^{-1}\right) ; R$ represents the gas constant which is equal to $8.314 \mathrm{~J} \cdot \mathrm{mol}^{-1} \cdot \mathrm{K}^{-1} ; T(\mathrm{~K})$ represents the operated temperature. According to the Eq. (5), the fitting result of different bio-chars was shown in Fig. S4 and Table 4.

As shown in Fig. S4, the data of three bio-chars all expressed good linear relation. According to Fig. S4, the Enthalpy change $\left(\Delta H^{\circ}\right)$ was calculated and listed in Table 4. The positive $\Delta H^{\circ}$ represented endothermic nature of chemical reaction, indicating that rising temperature promoted the occurrence of chemisorption. The $\Delta H^{\circ}$ of C6WNBr0.2 and C6WNI0.2 was 16.5 and $40.5 \mathrm{~kJ} \mathrm{~mol}^{-1}$, respectively. Therefore, rising testing temperature increased the chemisorption and adsorption capacity of C6WNBr0.2 and C6WNI0.2. On the contrary, the negative $\Delta H^{\circ}$ stood for exothermic nature of chemisorption, suggested that rising temperature inhabited the chemisorption occurrence and decreased the chemical adsorption. The $\Delta H^{\circ}$ of C6WNCl0.2 was $-16.2 \mathrm{~kJ} \cdot \mathrm{mol}^{-1}$, and hence it showed higher chemisorption character at low temperature. Though the temperature decreasing facilitated both physisorption and chemisorption for $\mathrm{C} 6 \mathrm{WNCl0.2}$, the facilitation for chemisorption was possibly more than for physisorption. Therefore, the C6WNCl0.2 showed high $R^{2}$ for pseudo-second order model and low $R^{2}$ for pseudo-first order model at low temperature.

Various halides modified AC and bio-chars have widely used in the coal-fired power plants. As discussed in introduction, the injection point usually contains two positions: before ESP and after ESP (TOXECON Techology). The process flow diagram of two AC injection technologies was shown in Fig. S5. The flue gas temperature from AC injection point to ESP outlet is in the range of $200-130{ }^{\circ} \mathrm{C}$. For TOXECON Technology, the flue gas temperature from AC injection point to FF outlet is in the range of $110-80{ }^{\circ} \mathrm{C}$. According to Fig 5, the temperature change has opposite influence on different halides modified bio-chars. The Br and I modified bio-chars are 
more geared to inject before ESP because high temperate $\left(200-130{ }^{\circ} \mathrm{C}\right)$ can promote their mercury adsorption capacity. In contrast, the $\mathrm{Cl}$ modified bio-char is more suitable for TOXECON Technology. The relatively low temperature makes $\mathrm{Cl}$ modified bio-char adsorbed more mercury. However, the $\mathrm{Cl}$ modified sorbent is often injected into before ESP in practice. These cases possibly cause resource and economic waste. As shown in Fig. 5A, the mercury adsorption capacity of C6WNCl0.2 is only $335.2 \mu \mathrm{g} \cdot \mathrm{g}^{-1}$ at $180{ }^{\circ} \mathrm{C}$ but $1118.9 \mu \mathrm{g} \cdot \mathrm{g}^{-1}$ at $60{ }^{\circ} \mathrm{C}$. The former value is only $30 \%$ of the latter one. The similar result is also seen in $\mathrm{Br}$ and I modified bio-chars. In Fig. 5B, the mercury adsorption capacity of C6WNBr0.2 is only 631.7 $\mu \mathrm{g} \cdot \mathrm{g}^{-1}$ at $60{ }^{\circ} \mathrm{C}$ yet $3089.4 \mu \mathrm{g} \cdot \mathrm{g}^{-1}$ at $180{ }^{\circ} \mathrm{C}$. The former value is only $20 \%$ of the latter one. This result indicates that improper application condition could result in invalidation of $70-80 \%$ adsorption capacity of sorbents. On the contrary, the correct AC injection position possibly reduces over half sorbent application. Andrew's study indicated that the cost of mercury control ranged from 3810-166000 dollars per pound of mercury removed [7]. Therefore, the correct injection way will save huge costs of mercury pollution control. As for this point, this research result has an important guidance significance for the application of halide modified sorbent in the future.

\subsection{The TPDT study}

According to above testing and modeling analyses, the mercury capture of halide modified bio-chars mainly depended on chemisorption. The temperature program desorption technic (TPDT) is widely used to analyze adsorption state of adsorbate since desorption process is related to the adsorption energy. Chemical adsorption is controlled by strong chemical bonds formed between the adsorbate and chemisorption sites. Thereby, the breaking of chemical bonds usually require more energy under high desorption temperature. On the contrary, the desorption of physisorbed mercury needs relatively lower temperature because bonds are weak for physical adsorption based on van der Waals' force. In this study, the TPDT result was used to judge adsorption mechanism via analyzing desorption energy of mercury on various bio-chars after adsorption experiment. The energy of mercury desorption from 
bio-chars was calculated via desorption rate $(-d \theta / d T)$, which is described as follows $[27,28]$ :

$$
-\frac{d \theta}{d T}=\frac{v}{\beta} \theta^{n} \exp \left(-\frac{E_{d}(1-\alpha \theta)}{R T}\right)
$$

Where $v$ is the pre-exponential factor; $\theta$ is the adsorbate coverage at temperature $T$; $\beta$ is the heating rate $(\mathrm{d} T / d t) ; \mathrm{n}$ is the order of desorption process; $E_{d}$ is the desorption energy; and $\alpha$ is the intermolecular parameter, negative value of $\alpha$ represents attractive intermolecular interactions and positive one represents repulsive intermolecular interactions. The desorption experiment data of various bio-chars was fitted with Eq. (6) via Matlab software. This fitting procedure used $v, E_{d}$ and $\alpha$ as free parameters that were allowed to vary to optimize fitting result. All desorption experiments was consider as one order of desorption process $(n=1)$. The fitting result reflected that the $v$ was in the range of $10^{8.8} \sim 10^{9.2}$ and $\alpha$ in the range of $0.018 \sim 0.021$. The calculated desorption energy of various bio-chars was shown in Table 5.

As shown in Fig. 7, the TPDT spectra of different bio-chars distributed over a wide temperature range, indicating the mercury adsorbed on bio-chars involved different types of adsorption sites. In case of C6W, two characteristic peak of mercury desorption appeared at temperature around $205{ }^{\circ} \mathrm{C}$ and $287{ }^{\circ} \mathrm{C}$ in Fig. 7A. The $\mathrm{Hg}^{0}$ desorbed at two temperatures, indicating that it seems to exist two different adsorption states at least. However, the bio-chars of C6WNCl0.2, C6WNBr0.2 and C6WNI0.2 showed only one peak at 377,360 and $353{ }^{\circ} \mathrm{C}$, respectively. The calculated desorption energy of C6W, C6WNCl0.2, C6WNBr0.2 and C6WNI0.2 was listed in Table 5. The desorption energy calculated from first peak of C6W was $32.5 \mathrm{~kJ} \cdot \mathrm{mol}^{-1}$, indicating that it was related with weakly adsorbed or physisorbed mercury. The desorption energy of second desorption peak at $287{ }^{\circ} \mathrm{C}$ was $60.2 \mathrm{~kJ} \cdot \mathrm{mol}^{-1}$. This implied a stronger adsorbed mercury compound, which was possibly caused by oxygen-containing functional groups. The area of first peak was bigger than second peak. This result suggested that physical adsorption was more important than functional group adsorption for C6W. The desorption energy of C6WNC10.2, C6WNBr0.2 and 
C6WNI0.2 was $82.1,81.7$ and $80.9 \mathrm{~kJ} \cdot \mathrm{mol}^{-1}$, respectively, which was higher than C6W. This result implied that ammonia halide modified bio-chars captured mercury via chemisorption. Therefore, halide modification changed mercury capture pattern from physisorption to chemisorption. Combining with mercury adsorption capacity of modified bio-chars and C6W, it inferred that the chemisorption was more important than physisorption for mercury removal.

\subsection{XPS analysis and chemisorption mechanism exploration}

To explore chemical reaction mechanism of mercury adsorption, the XPS was applied to investigating the valence state change of $\mathrm{Cl}, \mathrm{Br}, \mathrm{I}$ and $\mathrm{Hg}$ on the bio-chars. The analysis result was shown in Fig. 8. In Fig. 8A, two peaks appeared on the XPS spectrum of fresh and used $\mathrm{C} 6 \mathrm{WNCl0} 0.2$ at $\mathrm{Cl} 2 \mathrm{p}$, which belonged to the ionic $\mathrm{Cl}^{-}$ (198.2 eV) and C-Cl groups (200.0 eV), respectively [29]. In Fig. 8B, there were also two peaks appearing at the $68.2 \mathrm{eV}\left(\mathrm{Br}^{-}\right)$and $70.9 \mathrm{eV}(\mathrm{C}-\mathrm{Br})$ on the surface of fresh and used C6WNBr0.2 [30-32]. The spectrum of fresh and used C6WNI0.2 had four peaks in Fig. 8C. The peaks at $620.9 \mathrm{eV}$ and $532.6 \mathrm{eV}$ both stood for the $\mathrm{C}-\mathrm{I}$ groups and the peaks at $619.4 \mathrm{eV}$ and $630.8 \mathrm{eV}$ belonged to the ionic $\mathrm{I}^{-}$groups [32]. As shown in Fig. 8D, there was no obvious peak at $\mathrm{Hg} 4 \mathrm{f}$ on the spectrum of fresh C6WNI0.2. However, after mercury adsorption testing, two peaks representing $\mathrm{Hg}^{2+}$ centered at $100.6 \mathrm{eV}$ and $104.6 \mathrm{eV}$, indicating that the adsorbed mercury existed in the form of oxidation on the bio-chars [30, 33]. The similar result is found in bio-cahrs C6WNBr0.2 and C6WNCl0.2 in Fig. S6. The peak area ratio of different valence state halides was listed on the Table 6 to further investigate the mercury adsorption mechanism.

As shown in Table 6, via contrasting three bio-chars prior to and after the adsorption testing, three halide modified bio-chars got a uniform principle: covalent halides group ratio all decreased and ionic group ratio ascended after adsorption testing. This indicated that some covalent halides groups translated into the ionic groups during the adsorption process. Combining the existence form of oxidation state mercury, it could be proved that the covalent halide groups oxidized elemental 
mercury into mercuric halides, such as $\mathrm{HgCl}_{2}, \mathrm{HgBr}_{2}$ and $\mathrm{HgI}_{2}$. Therefore, the covalent halide groups were considered to be chemical adsorption sites of elemental mercury. In term of this point, the higher ratio of covalent halide groups possibly represented the more mercury adsorption sites and better adsorption capacity. Thereby, according to Table 6 , the mercury adsorption performance of three modified bio-chars followed the order: C6WNI0.2 > C6WNBr0.2 > C6WNC10.2.

The amout of $\mathrm{C}-\mathrm{X}$ groups determine the mercury removal performance of various modified bio-chars. The reason for different covalent halide group ratio of three bio-chars was possibly attributed to two aspects. On one hand, the halide ions expressed different reducibility $\left(\mathrm{I}^{-}>\mathrm{Br}^{-}>\mathrm{Cl}^{-}\right)$. The halide ion with higher reducibility was easier to donate electron and form covalent bonds with carbon atom. Hence, on the basis of the reducibility of halide ions, covalent group ratio should follow the order: $\mathrm{I}^{-}>\mathrm{Br}^{-}>\mathrm{Cl}^{-}$. On the other hand, the halide ion with bigger size possibly provided more chance to react with carbon atom and form covalent bonds. In term of this point, the covalent group ratio of halides modified bio-chars should also follow above order: $\mathrm{I}^{-}>\mathrm{Br}^{-}>\mathrm{Cl}^{-}$. Moreover, according to Table 6 , the result of halide covalent group ratio (C6WNI0.2 > C6WNBr0.2 > C6WNC10.2) supported above two inference.

This discovery possibly explained different adsorption performance of halides modified bio-chars from chemical property aspect. According to above analysis and previous studies, the mechanism of halide modified bio-chars could be described as follow: (1) the halide ions reacted with carbon atom to form the halide covalent bonds; (2) the elemental mercury transferred from gas phase to the surface of bio-chars; (3) the halide covalent groups oxidized elemental mercury into mercury halides. The mechanism of halide modified bio-chars could be described as follow (X represents the $\mathrm{Cl}, \mathrm{Br}$, and I) $[14,34]$ :

$\mathrm{Hg}^{0}{ }_{(\mathrm{g})} \rightarrow \mathrm{Hg}^{0}{ }_{(\mathrm{ad})}$

$\mathrm{C}+\mathrm{X}^{-} \rightarrow \mathrm{C}-\mathrm{X}$

$2 \mathrm{Hg}^{0}{ }_{(\mathrm{ad})}+2 \mathrm{C}-\mathrm{X}_{(\mathrm{ad})} \rightarrow \mathrm{Hg}_{2} \mathrm{X}_{2(\mathrm{ad})}$ 
$\mathrm{Hg}^{0}(\mathrm{ad})+2 \mathrm{C}-\mathrm{X}_{(\mathrm{ad})} \rightarrow \mathrm{HgX}_{2}$ (ad)

$\mathrm{Hg}_{2} \mathrm{X}_{2(\mathrm{ad})}+2 \mathrm{C}-\mathrm{X}_{(\mathrm{ad})} \rightarrow 2 \mathrm{HgX}_{2(\mathrm{ad})}$

This result indicates that the effective groups are the key factor deciding the mercury adsorption capacity of halide modified bio-chars. The preparation process of mercury sorbent should focus on improving the formation of C-X groups. Therefore, the carbon-based carrier materials are better option for mercury adsorption sorbents [35].

\section{Conclusion}

This study investigated the mercury adsorption capacity of bio-chars modified with ammonium halides and judged the relative importance of physisorption and chemisorption. According to the kinetic modeling, the difference of enthalpy change determined that high testing temperature improved adsorption capacity of C6WNI0.2 and C6WNBr0.2 yet lowered that of C6WNCl0.2. Halides modification increased desorption energy of adsorbed halide mercury from 32.5 to $80.9-82.1 \mathrm{~kJ} \cdot \mathrm{mol}^{-1}$ since adsorption mechanism changed from physisorption to chemisorption. The amount difference of $\mathrm{C}$-X groups serving as chemisorption sites decided halide modification effect order, which is $\mathrm{NH}_{4} \mathrm{I}>\mathrm{NH}_{4} \mathrm{Br}>\mathrm{NH}_{4} \mathrm{Cl}$. This study offers a guidance for application and preparation of mercury sorbents. This study indicates that proper application condition could increase $70-80 \%$ adsorption capacity of sorbents and hence correct injection position possibly reduces over half sorbent application.

\section{Acknowledgements}

This work was sponsored by the Major State Basic Research Development Program of China (973 Program) (No. 2013CB430000) and National Science Foundation of China (21521064). We are grateful to the great help offered by professor Boxiong Shen. 


\section{References}

[1] E.G. Pacyna, J.M. Pacyna, K. Sundseth, J. Munthe, K. Kindbom, S. Wilson, F. Steenhuisen, P. Maxson, Global emission of mercury to the atmosphere from anthropogenic sources in 2005 and projections to 2020, Atmospheric Environment, 44 (2010) 2487-2499.

[2] Y. Cao, C.-M. Cheng, C.-W. Chen, M. Liu, C. Wang, W.-P. Pan, Abatement of mercury emissions in the coal combustion process equipped with a Fabric Filter Baghouse, Fuel, 87 (2008) 3322-3330.

[3] P.S. Nolan, K.E. Redinger, G.T. Amrhein, G.A. Kudlac, Demonstration of additive use for enhanced mercury emissions control in wet FGD systems, Fuel Processing Technology, 85 (2004) 587-600.

[4] L. Zhang, S. Wang, Q. Wu, F. Wang, C.-J. Lin, L. Zhang, M. Hui, M. Yang, H. Su, J. Hao, Mercury transformation and speciation in flue gases from anthropogenic emission sources: a critical review, Atmospheric Chemistry and Physics, 16 (2016) 2417-2433.

[5] J.H. Pavlish, M.J. Holmes, S.A. Benson, C.R. Crocker, K.C. Galbreath, Application of sorbents for mercury control for utilities burning lignite coal, Fuel Processing Technology, 85 (2004) 563-576.

[6] E.J. Granite, M.C. Freeman, R.A. Hargis, W.J. O'Dowd, H.W. Pennline, The thief process for mercury removal from flue gas, J Environ Manage, 84 (2007) 628-634.

[7] A.P. Jones, J.W. Hoffmann, D.N. Smith, T.J. Feeley, J.T. Murphy, DOE/NETL's Phase II Mercury Control Technology Field Testing Program: Preliminary Economic Analysis of Activated Carbon Injection, Environmental Science \& Technology, 41 (2007) 1365-1371.

[8] T. Shu, P. Lu, N. He, Mercury adsorption of modified mulberry twig chars in a simulated flue gas, Bioresource Technology, 136 (2013) 182-187.

[9] Z. Tan, L. Sun, J. Xiang, H. Zeng, Z. Liu, S. Hu, J. Qiu, Gas-phase elemental mercury removal by novel carbon-based sorbents, Carbon, 50 (2012) 362-371.

[10] K. Yang, J. Peng, C. Srinivasakannan, L. Zhang, H. Xia, X. Duan, Preparation of high surface area activated carbon from coconut shells using microwave heating, Bioresource Technology, 101 (2010) 6163-6169.

[11] S. Tao, C. Li, X. Fan, G. Zeng, P. Lu, X. Zhang, Q. Wen, W. Zhao, D. Luo, C. Fan, Activated coke impregnated with cerium chloride used for elemental mercury removal from simulated flue gas, Chemical Engineering Journal, 210 (2012) 547-556.

[12] J. Cai, B. Shen, Z. Li, J. Chen, C. He, Removal of elemental mercury by clays impregnated with KI and $\mathrm{KBr}$, Chemical Engineering Journal, 241 (2014) 19-27.

[13] M. De, R. Azargohar, A.K. Dalai, S.R. Shewchuk, Mercury removal by bio-char based modified activated carbons, Fuel, 103 (2013) 570-578.

[14] S. Lee, Removal of gas-phase elemental mercury by iodine- and chlorine-impregnated activated carbons, Atmospheric Environment, 38 (2004) 4887-4893.

[15] J.A. Korpiel, R.D. Vidic, Effect of Sulfur Impregnation Method on Activated Carbon Uptake of Gas-Phase Mercury, Environmental Science \& Technology, 31 (1997) 2319-2325.

[16] G. Li, B. Shen, Y. Wang, S. Yue, Y. Xi, M. An, K. Ren, Comparative study of element mercury removal by three bio-chars from various solid wastes, Fuel, 145 (2015) 189-195.

[17] B. Shen, G. Li, F. Wang, Y. Wang, C. He, M. Zhang, S. Singh, Elemental mercury removal by the modified bio-char from medicinal residues, Chemical Engineering Journal, 272 (2015) 28-37.

[18] Y. Zhuang, C. Martin, J. Pavlish, F. Botha, Cobenefit of SO3 reduction on mercury capture with activated carbon in coal flue gas, Fuel, 90 (2011) 2998-3006.

[19] Y.H. Li, C.W. Lee, B.K. Gullett, Importance of activated carbon's oxygen surface functional groups on elemental mercury adsorption, Fuel, 82 (2003) 451-457. 
[20] G. Li, B. Shen, Y. Li, B. Zhao, F. Wang, C. He, Y. Wang, M. Zhang, Removal of element mercury by medicine residue derived biochars in presence of various gas compositions, J Hazard Mater, 298 (2015) 162-169.

[21] G. Li, B. Shen, F. Li, L. Tian, S. Singh, F. Wang, Elemental mercury removal using biochar pyrolyzed from municipal solid waste, Fuel Processing Technology, 133 (2015) 43-50.

[22] J.C. Groen, L.A.A. Peffer, J. Pérez-Ramírez, Pore size determination in modified micro- and mesoporous materials. Pitfalls and limitations in gas adsorption data analysis, Microporous and Mesoporous Materials, 60 (2003) 1-17.

[23] G. Skodras, I. Diamantopoulou, G. Pantoleontos, G.P. Sakellaropoulos, Kinetic studies of elemental mercury adsorption in activated carbon fixed bed reactor, Journal of Hazardous Materials, 158 (2008) 1-13.

[24] H.-C. Hsi, C.-Y. Tsai, T.-H. Kuo, C.-S. Chiang, Development of low-concentration mercury adsorbents from biohydrogen-generation agricultural residues using sulfur impregnation, Bioresource Technology, 102 (2011) 7470-7477.

[25] Z. Reddad, C. Gerente, Y. Andres, P. Le Cloirec, Adsorption of Several Metal Ions onto a Low-Cost Biosorbent: Kinetic and Equilibrium Studies, Environmental Science \& Technology, 36 (2002) 2067-2073.

[26] R.D. Vidic, D.P. Siler, Vapor-phase elemental mercury adsorption by activated carbon impregnated with chloride and chelating agents, Carbon, 39 (2001) 3-14.

[27] S. Kwon, E. Borguet, R.D. Vidic, Impact of Surface Heterogeneity on Mercury Uptake by Carbonaceous Sorbents under UHV and Atmospheric Pressure, Environmental Science \& Technology, 36 (2002) 4162-4169.

[28] K.R. Paserba, A.J. Gellman, Effects of conformational isomerism on the desorption kinetics of n-alkanes from graphite, The Journal of Chemical Physics, 115 (2001) 6737.

[29] A. Pérez-Cadenas, amp, x, F. n, F.J. Maldonado-Hódar, C. Moreno-Castilla, On the nature of surface acid sites of chlorinated activated carbons, Carbon, 41 (2003) 473-478.

[30] N.D. Hutson, B.C. Attwood, K.G. Scheckel, XAS and XPS Characterization of Mercury Binding on Brominated Activated Carbon, Environmental Science \& Technology, 41 (2007) 1747-1752.

[31] B.V. Crist, KBr Crystal: Cleaved in Air, Surface Science Spectra, 1 (1992) 292.

[32] X.L. Zhou, F. Solymosi, P.M. Blass, K.C. Cannon, J.M. White, Interactions of methyl halides (Cl, $\mathrm{Br}$ and I) with $\mathrm{Ag}(111)$, Surface Science, 219 (1989) 294-316.

[33] P. Behra, P. Bonnissel-Gissinger, M. Alnot, R. Revel, J.J. Ehrhardt, XPS and XAS study of the sorption of $\mathrm{Hg}$ (II) onto pyrite, Langmuir, 17 (2001) 3970-3979.

[34] S.-H. Lee, Y.-O. Park, Gas-phase mercury removal by carbon-based sorbents, Fuel Processing Technology, 84 (2003) 197-206.

[35] G. Li, S. Wang, Q. Wu, F. Wang, B. Shen, Mercury sorption study of halides modified bio-chars derived from cotton straw, Chemical Engineering Journal, 302 (2016) 305-313. 


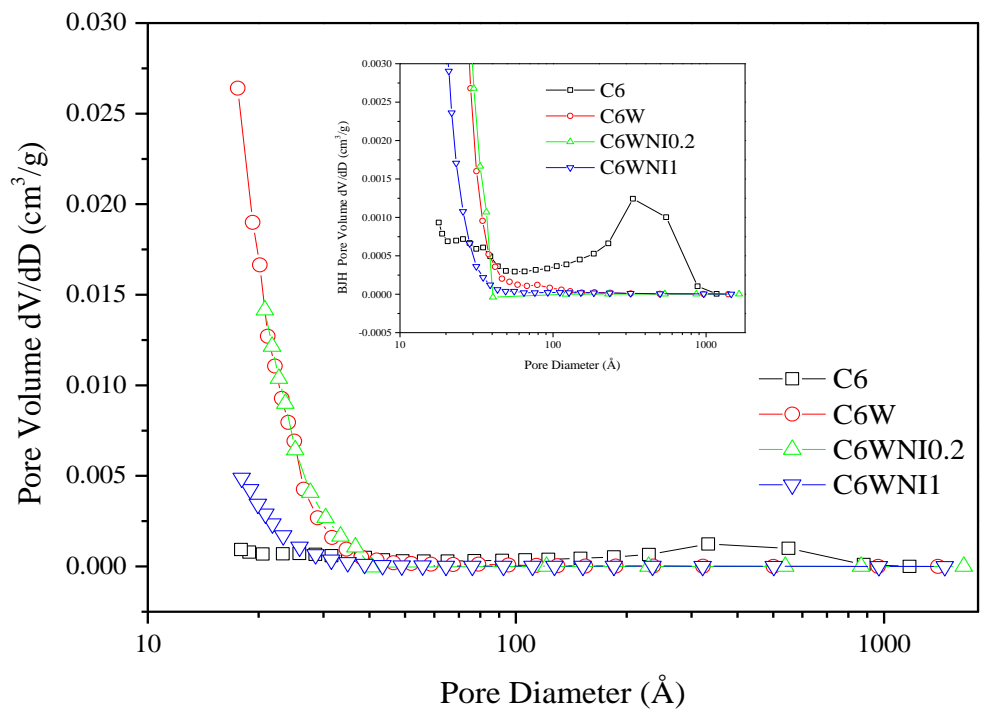

Fig. 1 Pore distribution of bio-chars (Inset: pore distribution in mesopore and macropore) 

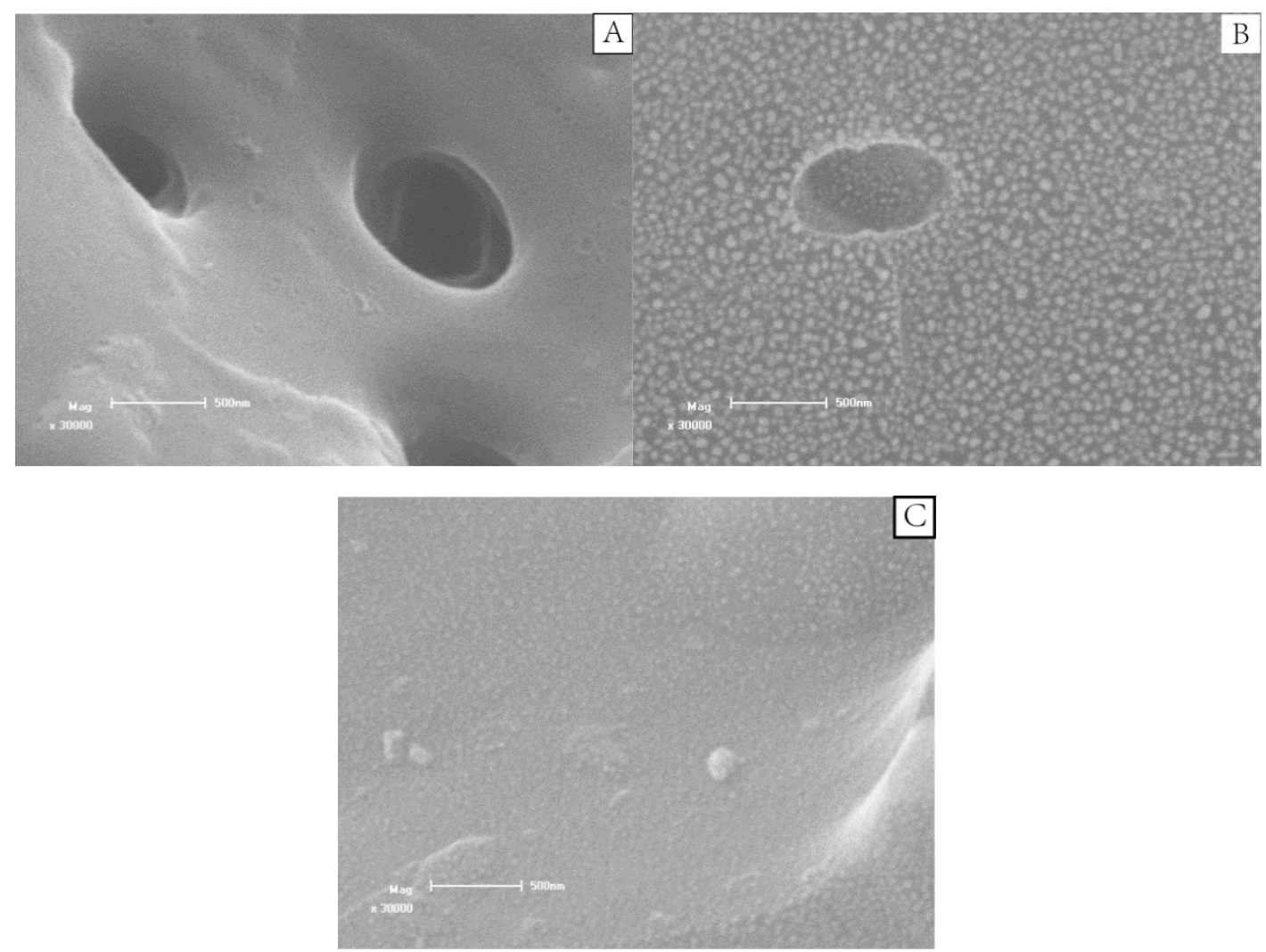

Fig. 2 SEM images of bio-chars, A: C6W; B: C6WNI0.2; C: C6WNI1 


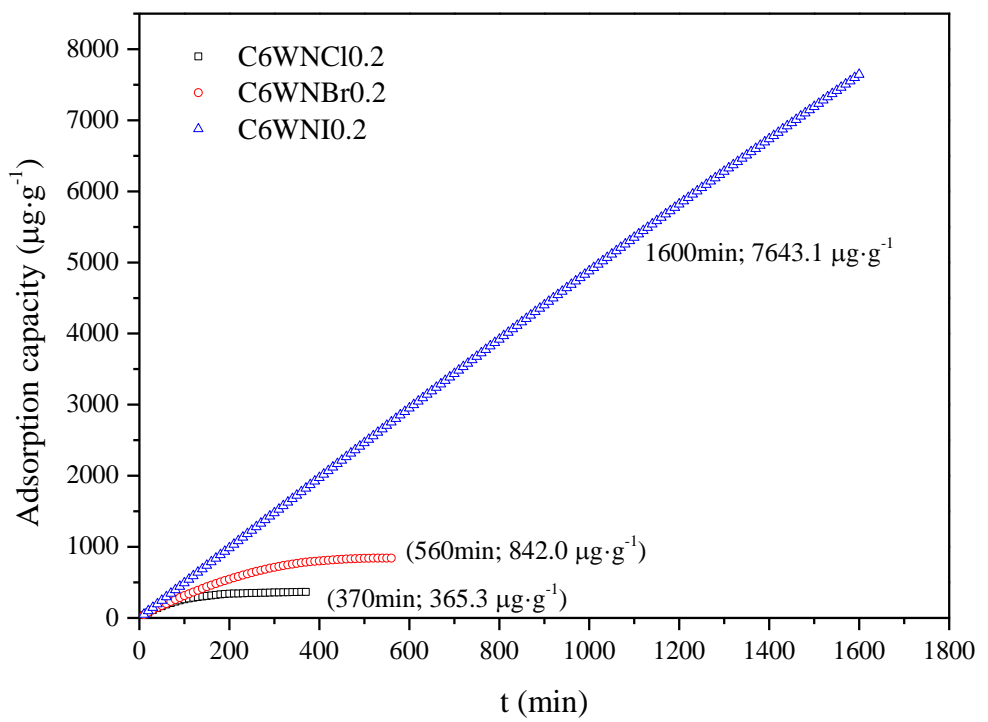

Fig. 3 Effect of three halides on $\mathrm{Hg}^{0}$ adsorption at $120{ }^{\circ} \mathrm{C}$ 

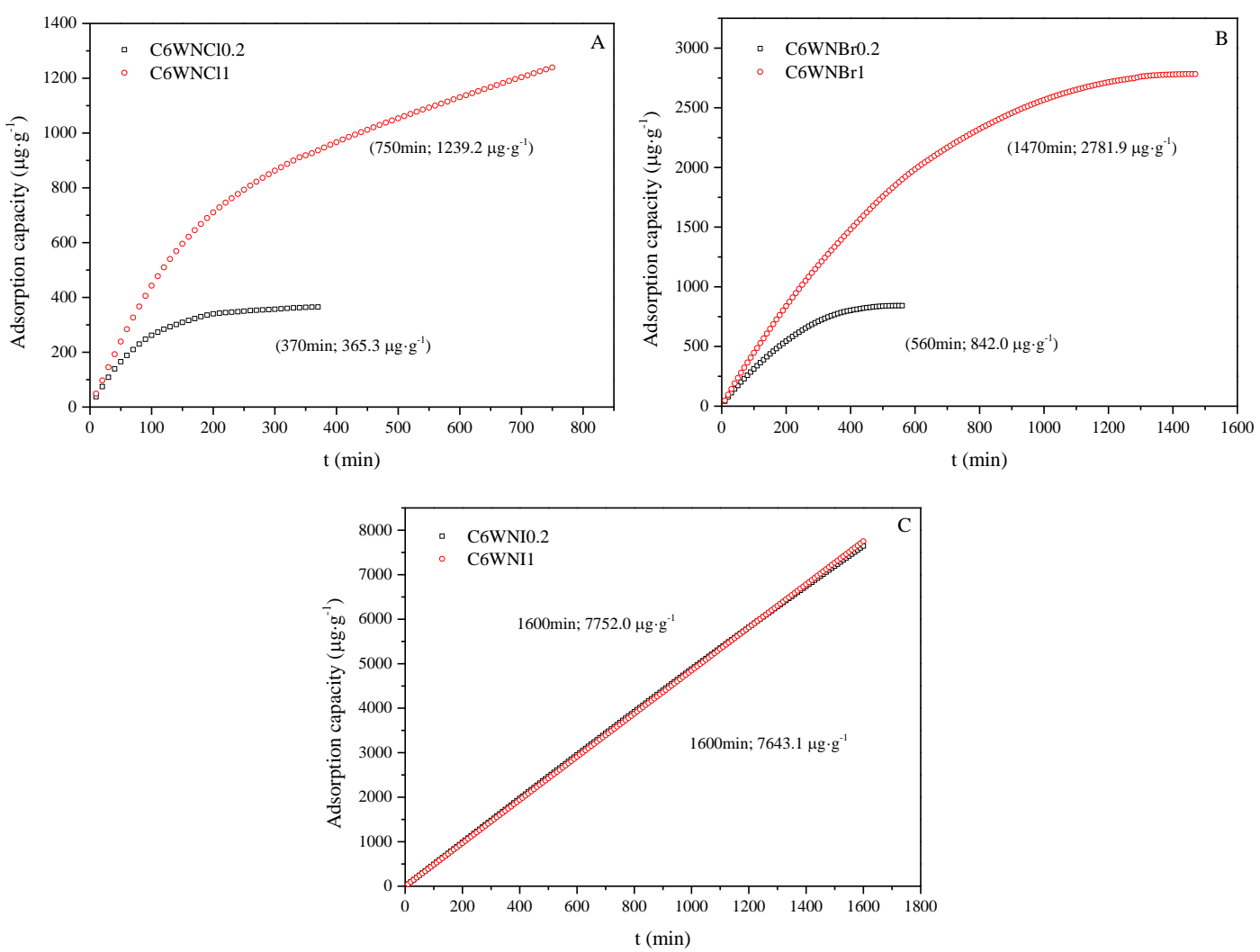

Fig. 4 Effect of loading on $\mathrm{Hg}^{0}$ adsorption at $120{ }^{\circ} \mathrm{C}$

A: $\mathrm{NH}_{4} \mathrm{Cl} ; \mathrm{B}: \mathrm{NH}_{4} \mathrm{~B}_{\mathrm{r}} ; \mathrm{C}: \mathrm{NH}_{4} \mathrm{I}$ 

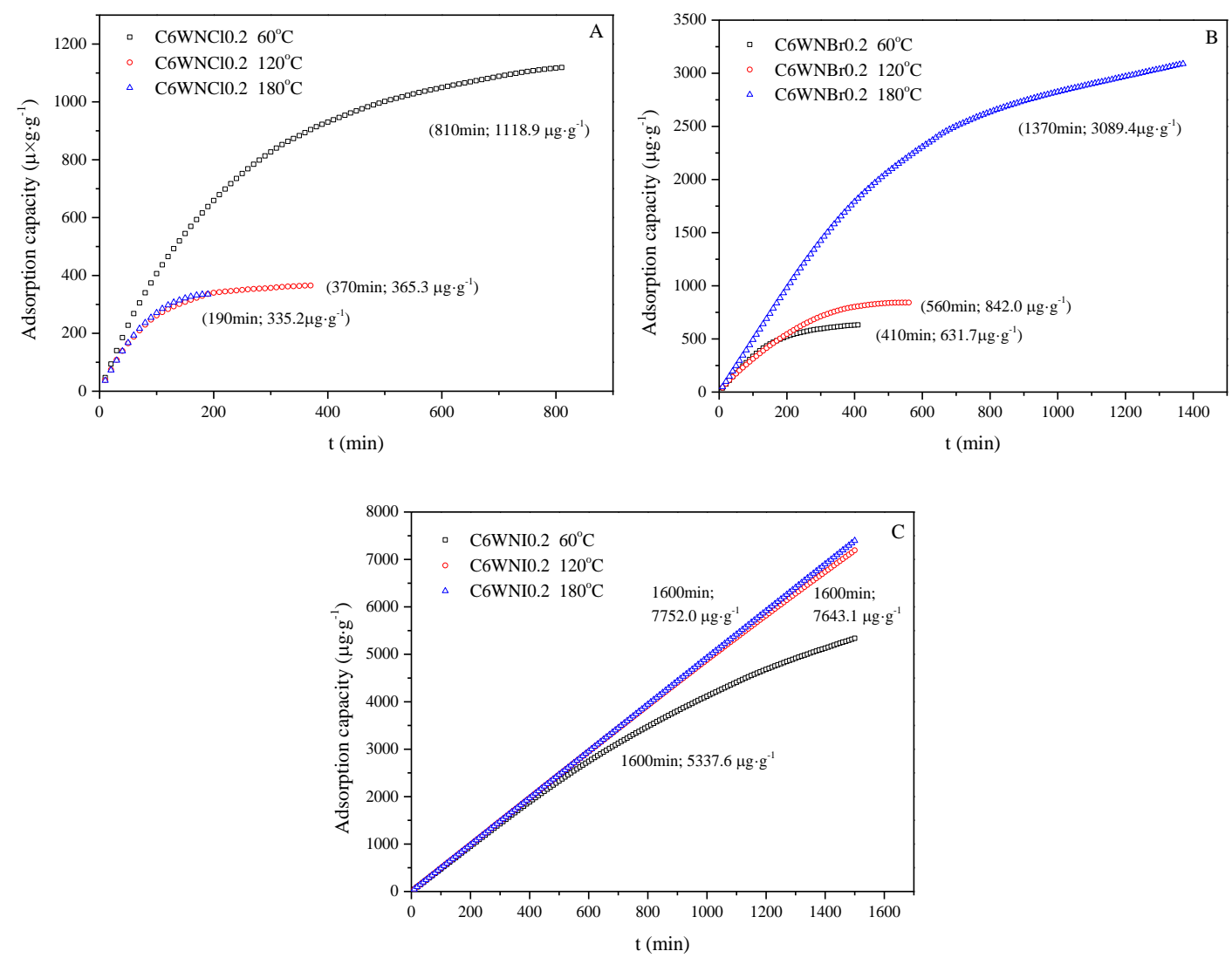

Fig. 5 Effect of testing temperature on $\mathrm{Hg}^{0}$ adsorption

A: C6WNCl0.2; B: C6WNBr0.2; C: C6WNI0.2 

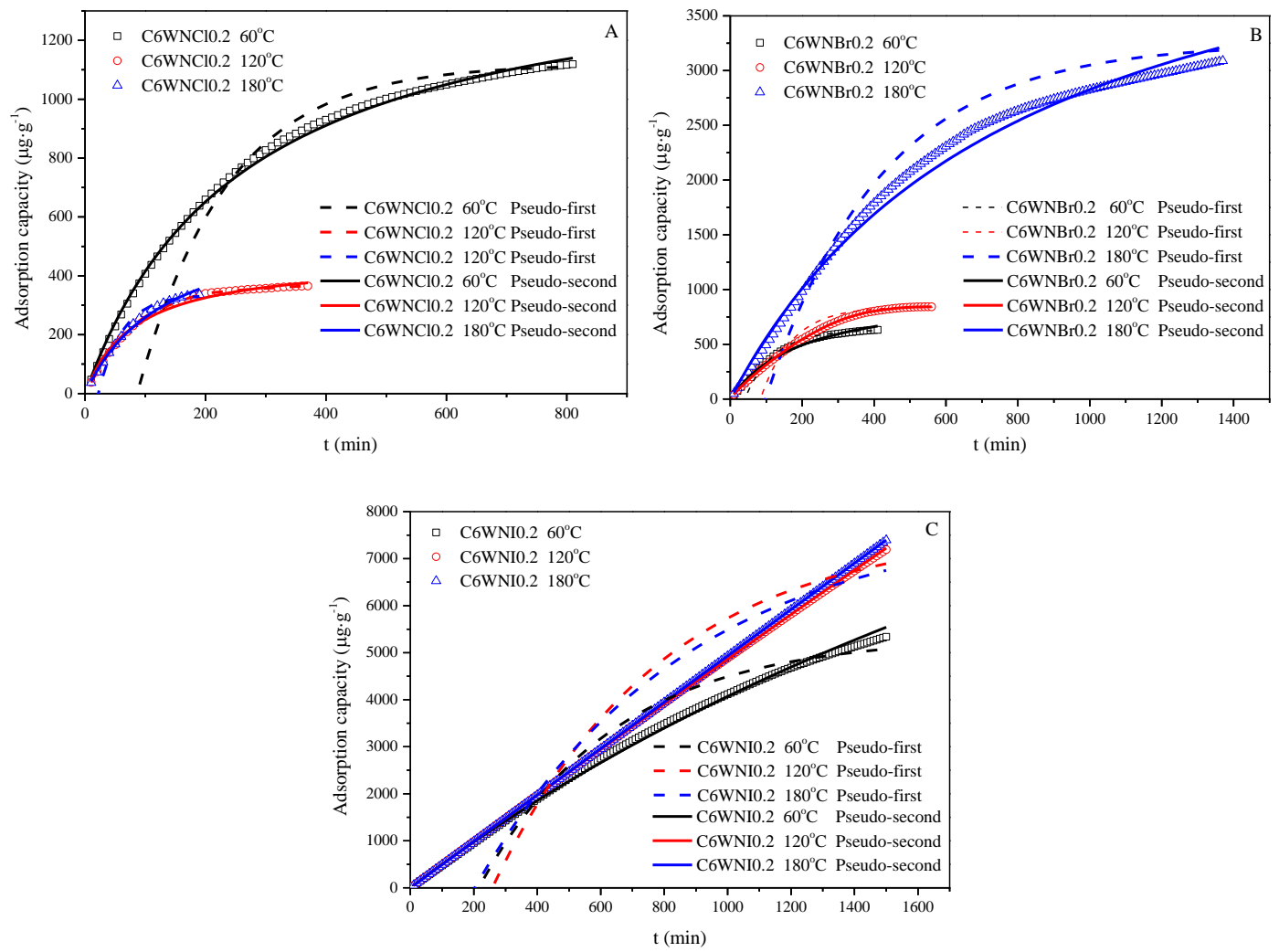

Fig. 6 Kinetic analysis of bio-chars by pseudo-first order model and pseudo-second order model

A: C6WNCl0.2; B: C6WNBr0.2; C: C6WNI0.2 

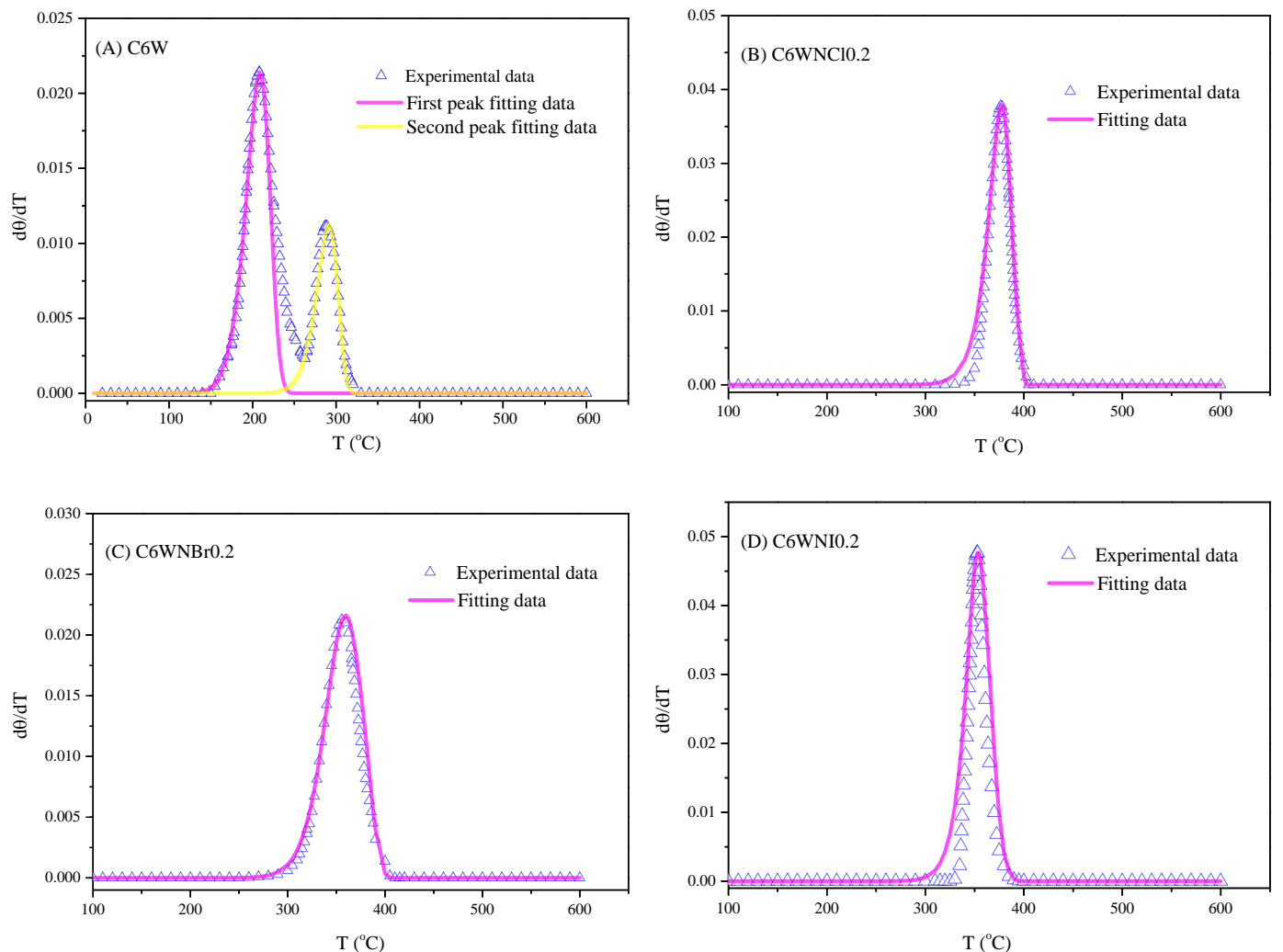

Fig. 7 The TPDT experimental data and fitting analysis of various bio-chars, (A) C6W; (B)

C6WNCl0.2; (C) C6WNBr0.2; (D) C6WNI0.2 

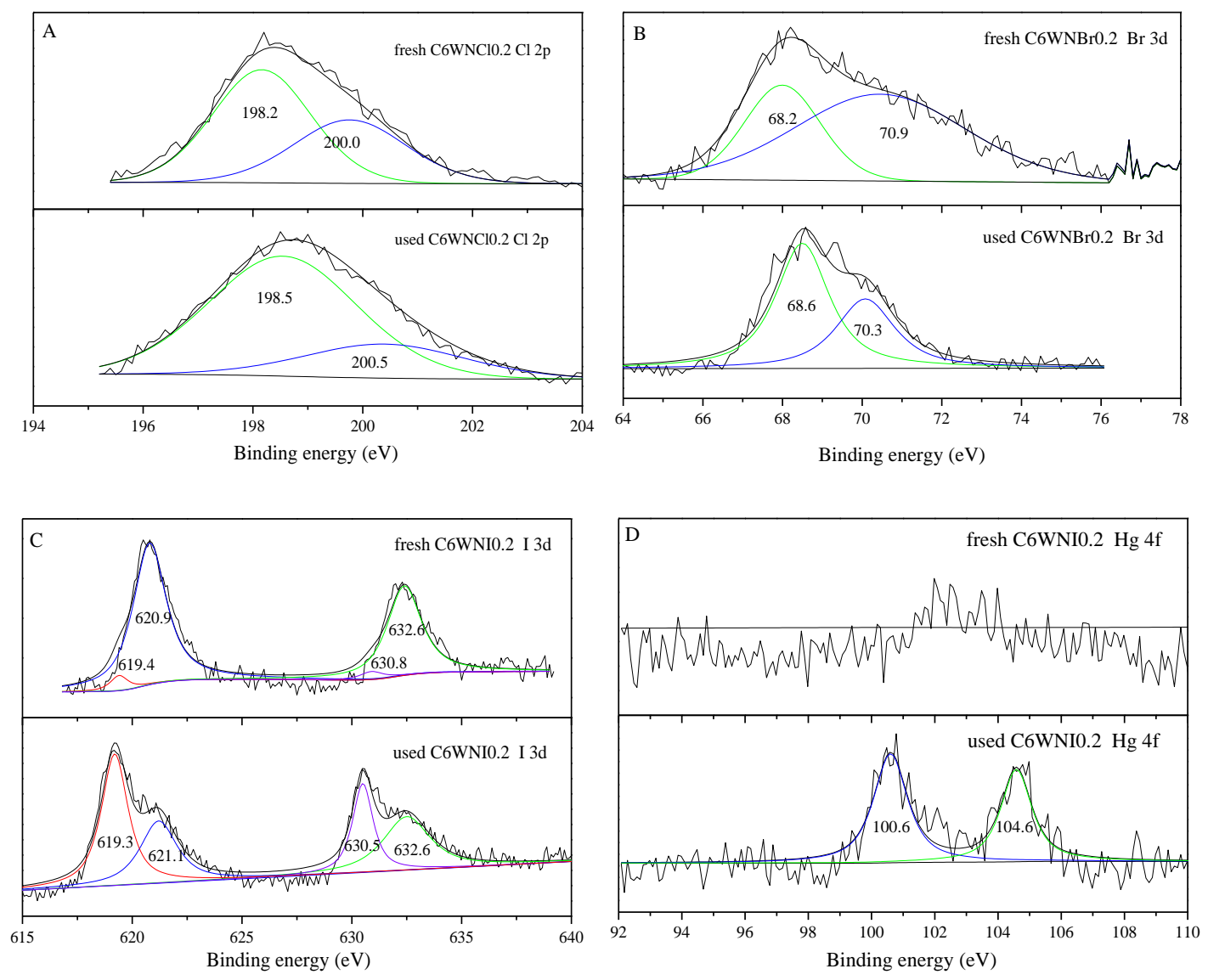

Fig. 8 XPS analysis of bio-chars 
Table 1 Proximate and ultimate analysis of raw materials

\begin{tabular}{|c|c|c|c|c|c|c|c|c|}
\hline \multirow[t]{2}{*}{ Sample } & \multicolumn{4}{|c|}{ Proximate analysis (wt. \%) } & \multicolumn{4}{|c|}{ Ultimate analysis (wt.\%) } \\
\hline & Moisture & Volatile & Ash & FC & $\mathrm{C}$ & $\mathrm{H}$ & $\mathrm{O}$ & $\mathrm{N}$ \\
\hline Cotton straw & 0.2 & 63.0 & 8.3 & 28.5 & 43.6 & 5.8 & 49.8 & 0.8 \\
\hline
\end{tabular}


Table 2 Pore structural parameters of samples

\begin{tabular}{llllllll}
\hline Sample & $\begin{array}{l}\mathrm{S}_{\text {BET }} \\
\left(\mathrm{m}^{2} \cdot \mathrm{g}^{-1}\right)\end{array}$ & $\begin{array}{l}\mathrm{S}_{\text {BETmicro }} \\
\left(\mathrm{m}^{2} \cdot \mathrm{g}^{-1}\right)\end{array}$ & $\begin{array}{l}\mathrm{S} \% \\
(\%)\end{array}$ & $\begin{array}{l}\mathrm{V}_{\text {total }} \\
\left(\mathrm{cm}^{2} \cdot \mathrm{g}^{-1}\right)\end{array}$ & $\begin{array}{l}\mathrm{V}_{\text {micro }} \\
\left(\mathrm{cm}^{2} \cdot \mathrm{g}^{-1}\right)\end{array}$ & $\begin{array}{l}\mathrm{V} \% \\
(\%)\end{array}$ & $\begin{array}{l}\mathrm{D} \\
(\mathrm{A})\end{array}$ \\
\hline C6 & 226.4 & 125.8 & $55.6 \%$ & 0.145 & 0.026 & $20.8 \%$ & 39.1 \\
C6W & 453.5 & 294.2 & $64.9 \%$ & 0.222 & 0.136 & $61.3 \%$ & 20.0 \\
C6WNI0.2 & 388.0 & 194.5 & $50.1 \%$ & 0.208 & 0.088 & $42.3 \%$ & 30.8 \\
C6WNI1 & 158.6 & 78.3 & $49.4 \%$ & 0.084 & 0.033 & $39.3 \%$ & 31.4 \\
C6WNBr0.2 & 449.3 & 239.9 & $53.4 \%$ & 0.221 & 0.121 & $54.8 \%$ & 23.0 \\
C6WNBr1 & 218.6 & 117.0 & $53.5 \%$ & 0.115 & 0.053 & $46.1 \%$ & 27.5 \\
C6WNC10.2 & 424.1 & 224.3 & $52.9 \%$ & 0.210 & 0.095 & $45.2 \%$ & 24.1 \\
C6WNC11 & 184.4 & 94.3 & $51.1 \%$ & 0.099 & 0.041 & $41.4 \%$ & 29.4 \\
\hline
\end{tabular}


Table 3 Fitting correlation coefficient of pseudo-first and pseudo-second order model

\begin{tabular}{llllllll}
\hline Sample & \multicolumn{2}{l}{ Pseudo-first order $\left(R^{2}\right)$} & & \multicolumn{3}{l}{ Pseudo-second order $\left(R^{2}\right)$} \\
\cline { 2 - 3 } \cline { 6 - 8 } & $60{ }^{\circ} \mathrm{C}$ & $120{ }^{\circ} \mathrm{C}$ & $180{ }^{\circ} \mathrm{C}$ & & $60{ }^{\circ} \mathrm{C}$ & $120{ }^{\circ} \mathrm{C}$ & $180{ }^{\circ} \mathrm{C}$ \\
\hline C6WNC10.2 & 0.63 & 0.94 & 0.93 & & 0.99 & 0.97 & 0.96 \\
C6WNBr0.2 & 0.93 & 0.89 & 0.88 & & 0.96 & 0.97 & 0.98 \\
C6WNI0.2 & 0.90 & 0.88 & 0.85 & & 0.96 & 0.99 & 1.00 \\
\hline
\end{tabular}


Table 4 Enthalpy change $\left(\Delta H^{\circ}\right)$ of mercury adsorption reaction for three bio-chars

\begin{tabular}{llll}
\hline Sample & C6WNCl0.2 & C6WNBr0.2 & C6WNI0.2 \\
\hline$\Delta H^{o}\left(\mathrm{~kJ} \cdot \mathrm{mol}^{-1}\right)$ & -16.2 & 16.5 & 40.5 \\
\hline
\end{tabular}


Table 5 The calculated desorption energy

\begin{tabular}{lll}
\hline Sample & Desorption temperature $\left({ }^{\circ} \mathrm{C}\right)$ & Desorption energy $E_{d}\left(\mathrm{~kJ} \cdot \mathrm{mol}^{-1}\right)$ \\
\hline C6W (first peak) & 205 & 32.5 \\
C6W (second peak) & 287 & 60.2 \\
C6WNCl0,2 & 377 & 82.1 \\
C6WNBr0.2 & 360 & 81.7 \\
C6WNI0.2 & 353 & 80.9 \\
\hline
\end{tabular}


Table 6 Peak area ratio of different valence state halides

\begin{tabular}{llllllll}
\hline \multirow{2}{*}{ Groups } & \multirow{2}{*}{$\begin{array}{l}\text { Position } \\
\end{array}$} & \multicolumn{2}{l}{ C6WNCl0.2 } & \multicolumn{2}{l}{ C6WNBr0.2 } & \multicolumn{2}{l}{ C6WNI0.2 } \\
\cline { 3 - 8 } & & fresh & used & fresh & used & fresh & used \\
\hline $\mathrm{C}-\mathrm{Cl}$ & $200.2 \pm 0.3$ & $39.1 \%$ & $23.5 \%$ & - & - & - & - \\
$\mathrm{Cl}^{-}$ & $198.3 \pm 0.3$ & $60.9 \%$ & $76.5 \%$ & - & - & - & - \\
$\mathrm{C}-\mathrm{Br}$ & $70.6 \pm 0.3$ & - & - & $67.1 \%$ & $37.9 \%$ & - & - \\
$\mathrm{Br}^{-}$ & $68.4 \pm 0.2$ & - & - & $32.9 \%$ & $62.1 \%$ & - & - \\
$\mathrm{C}^{-}$ & $621.0 \pm 0.1$ & - & - & - & - & $94.5 \%$ & $39.5 \%$ \\
$\mathrm{I}^{-}$ & $619.3 \pm 0.1$ & - & - & - & - & $5.5 \%$ & $60.5 \%$ \\
\hline
\end{tabular}



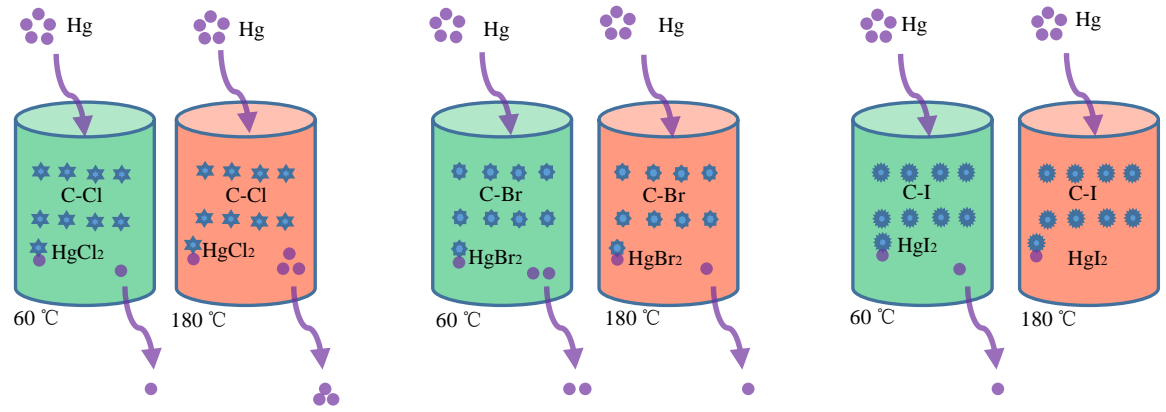